\title{
RELEVÂNCIA DAS TERRAS RARAS PARA O SETOR ENERGÉTICO
}

\author{
A. F. SILVA JUNIOR ${ }^{1 *}$ e M. F. DE CAMPOS ${ }^{2}$ \\ ${ }^{1}$ CEFET/RJ - Campus Angra dos Reis \\ ${ }^{2}$ Universidade Federal Fluminense \\ professoramilton@gmail.com*
}

Artigo submetido em novembro/2015 e aceito em novembro/2015

DOI: $10.15628 /$ holos. 2016.3753

\section{RESUMO}

As reservas de terras raras no Brasil são re-avaliadas. Terras raras podem ser obtidas como subproduto da extração de nióbio, tântalo e estanho. As principais aplicações de terras raras são discutidas. Entres essas aplicações encontram-se ímãs, fósforos luminescentes e catálise. Uma das aplicações de maior demanda em volume são ímãs NdPrFeB para turbinas gigantes de energia eólica. Lâmpadas fluorescentes estão sendo substituídas por lâmpadas de LED, reduzindo a demanda por Európio.

PALAVRAS-CHAVE: Terras Raras, Energia, Ímãs, Fósforos luminescentes, Turbinas eólicas.

\section{RELEVANCE OF RARE EARTH FOR THE ENERGY SECTOR}

\begin{abstract}
The rare earth reserves in Brazil are re-evaluated. Rare earths can be obtained as a byproduct of the extraction of niobium, tantalum and tin. The main applications of rare earth are discussed. Among these applications are magnets, luminescent phosphors and catalysis. One of
\end{abstract}

the highest volume on demand applications are NdPrFeB magnets for wind power giant turbines. fluorescent lamps are being replaced by LED lamps, reducing the demand for Europium.

KEYWORDS: Rare Earth, Energy, Magnets, luminescent matches, Wind turbines. 


\section{INTRODUÇÃO}

As reservas de terras raras no Brasil são re-avaliadas no presente estudo. O Brasil é um dos países com maiores reservas no mundo de terra-raras [1]. Outro país com significantes reservas é a China, responsável por mais de $90 \%$ da produção mundial [1]. As terra-raras tem diversas aplicações em alta tecnologia [2], e a extração de terra-raras no Brasil pode impactar positivamente essas indústrias. Por exemplo, o Brasil tem tradição em motores elétricos de alta eficiência energética, contando com empresas como WEG, Embraco e Tecumseh. Uma das maneiras de aumentar eficiência de motores é o emprego de ímãs NdPrFeB. Ímãs de NdPrFeB são a solução ideal para turbinas eólicas de grande porte, ficando assim evidente a relevância das terras raras para setor energético.

Estima-se que mais de $40 \%$ da energia elétrica no mundo é consumida em motores elétricos, então a otimização de motores deve ser seriamente considerada. A agência americana DOE recentemente estabeleceu regras para motores elétricos mais eficientes [3], [4], sendo rapidamente acompanhada pela agência de energia européia [5].

As maiores aplicações de terras-raras em termos de valor agregado são em ímãs e fósforos luminescentes. Neodímio, Praseodímio e Disprósio são empregados em ímãs, e Európio e Térbio em fósforos. Nd, Pr, Tb, Dy e Eu são as cinco terras raras com maior valor atualmente [6]. Ce e La têm diversas aplicações, mas são muito abundantes. Baterias $\mathrm{Ni}-\mathrm{M}-\mathrm{H}$ ( $\mathrm{M}=$ metal, como o lantânio) ainda são usadas, mas as baterias Li íon já estão dominando o mercado, e isso reduz a demanda por lantânio nas baterias Ni-M-H. Lantânio tem importante aplicação em catálise no refino de petróleo, e a Petrobrás consome anualmente 900 toneladas de óxido de Lantânio [7], usado na estabilização de zeólitas. Óxido de cério é usado em grande volume para polimento de vidros. A aplicação de Cério em lâmpadas de LED está aumentando.

Mineradores iniciantes na produção de terras raras devem levar em conta que o concentrado de terras raras tem baixíssimovalor comercial, e a separação de óxidos de terras raras é essencial para agregar valor [8]. Contudo, existem algumas aplicações de mischmetal (terras raras misturadas) em metalurgia e em baterias.

Também será comentada aqui a viabilidade econômica de produção de terras -raras. No ano de 2015 , os preços de terras-raras despencaram, devido a uma combinação de fatores que inclui superprodução na China e atividades de mineração na Austrália e Estados Unidos. Como consequência, projetos com custo acima de $10 \mathrm{U \$} / \mathrm{kg}$ são de difícil viabilidade econômica. A solução para o Brasil é obter terras raras como subproduto na mineração de nióbio, tântalo ou estanho, como será discutido a seguir.

\section{APLICAÇÕES}

As principais aplicações das terras raras serão brevemente discutidas. As terras raras são quimicamente muito semelhantes, e sua separação é difícil. Por isso, por muito tempo foi usado o "mischmetal", uma mistura de terras raras na forma metálica. As terras raras apenas ficaram disponíveis em grande quantidade nos anos 1960, quando a Rhone Poulenc aperfeiçoou o processo de extração por solvente [9]. Európio já era essencial nessa época, fornecendo o "melhor vermelho" para televisores coloridos. No início dos anos 1970, ímãs de SmCo permitiram miniaturização de muitos equipamentos, viabilizando por exemplo o Sony "Walkmen". 
Entretanto, quando as terras raras não são essenciais, tendem a ser substituídas por elementos de menor custo. A demanda está fortemente relacionada ao preço.

A grande maioria das aplicações é sumarizada na Tabela I. O carro híbrido Toyota Prius foi um exemplo clássico de aplicação de terras raras, vide Tabela II. A maioria das aplicações de terras raras é em alta tecnologia, como mostra a Tabela I.

Tabela I. Aplicações de Elementos Terras Raras

\begin{tabular}{|c|c|c|}
\hline Uso & \multicolumn{2}{|c|}{ Aplicações } \\
\hline Ímãs & $\begin{array}{l}\text { - } \text { Peças automotivas } \\
\text { - } \text { Atuadores } \\
\text { - } \text { Sistema antibloqueio } \\
\text { - } \text { Sistemas de comunicação } \\
\text { - Unidades de disco rígido e motores de } \\
\text { - } \text { Acionamento } \\
\text { - Rolamamento elétrico e de propulsão } \\
\text { - Ressonância magnética } \\
\text { - } \quad \text { Disco de armazenamento magnético }\end{array}$ & $\begin{array}{ll}\text { - } & \text { Refrigeração magnética } \\
\text { - } & \text { Ligas magnetostrictivas } \\
\text { - } & \text { Tecnologias de gravação magneto-óptica } \\
\text { - } & \text { Microfones e alto-falantes (a mplificação de } \\
\text { - } & \text { Tinal) } \\
\text { - } & \text { Motores (veículos híbridos) } \\
\text { - } & \text { Geração de energia (turbinas eólicas) } \\
\text { - } & \text { Radares }\end{array}$ \\
\hline Catalisadores & $\begin{array}{ll}\text { - } & \text { Refino de petróleo } \\
\text { - } & \text { O processamento químico } \\
\text { - } & \text { Os conversores catalíticos }\end{array}$ & $\begin{array}{ll}\text { - } & \text { Aditivos para diesel } \\
\text { - } & \text { Filtros de poluição industrial }\end{array}$ \\
\hline Eletrônica & $\begin{array}{l}\text { - } \quad \text { Tubos de raios catódicos(CRT) } \\
\text { - } \quad \text { Lâmpadas fluorescentes compactas } \\
\text { - } \quad \text { Os sistemas de comunicação } \\
\text { - } \quad \text { Fósforos Luminescentes } \\
\text { - } \quad \text { Contra-medidas el etrônicas } \\
\text { - } \quad \text { Fibra óptica } \\
\text { - } \quad \text { Posicionamento global por satélite (GPS) }\end{array}$ & $\begin{array}{ll}\text { - } & \text { Sistemas de orientação } \\
\text { - } & \text { Lasers } \\
\text { - } & \text { Display de cristal líquido (LCD) } \\
\text { - } & \text { Fósforos de imagens médicas } \\
\text { - } & \text { Sensores de temperatura ópticos } \\
\text { - } & \text { Plasma Display Panel } \\
\text { - } & \text { Smart phones }\end{array}$ \\
\hline Vidros & $\begin{array}{ll}\text { - } & \text { Lentes da câmera } \\
\text { - } & \text { Vidro óptico } \\
\text { - } & \text { Polimento compostos } \\
\text { - } & \text { Espelhos de controle térmico } \\
\end{array}$ & $\begin{array}{ll}\text { - } & \text { Vidro resistente UV } \\
\text { - } & \text { Imagiologia de raios-X } \\
\text { - } & \text { Telas coloridas }\end{array}$ \\
\hline Cerâmica & $\begin{array}{ll}\text { - } & \text { Capacitores } \\
\text { - } & \text { Corantes } \\
\end{array}$ & $\begin{array}{ll}\text { - } & \text { Sensores } \\
\text { - } & \text { Cintiladores } \\
\end{array}$ \\
\hline $\begin{array}{l}\text { Ligas } \\
\text { metálicas }\end{array}$ & $\begin{array}{l}\text { - } \quad \text { Peças de a eronaves e motores a jato } \\
\text { - } \quad \text { Alumínio / magnésio } \\
\text { - } \quad \text { Cerro fundido } \\
\text { - } \quad \text { Armalas de combustível } \\
\text { - }\end{array}$ & $\begin{array}{l}\text { - } \text { Pedras de isqueiro } \\
\text { - } \text { Baterias de níquel-hidreto metálico } \\
\text { - } \text { Aço } \\
\text { - Superligas }\end{array}$ \\
\hline Outros & $\begin{array}{ll}\text { - } & \text { Revestimentos } \\
\text { - } & \text { Fertilizantes } \\
\text { - } & \text { Traçadores médicos } \\
\text { - } & \text { Radioterapia } \\
\end{array}$ & $\begin{array}{l}\text { - } \quad \text { Barras de controle nuclear } \\
\text { - } \text { Pigmentos } \\
\text { - Baterias recarregáveis } \\
\text { - Tratamento de água }\end{array}$ \\
\hline
\end{tabular}

Com o pico de preço de terras raras em 2010-2011, as aplicações envolvendo terras raras foram sendo diminuídas. Ímãs, fósforos luminescentes e catálise estão entre as principais aplicações, mas não são as únicas, conforme mostra a Tabela I. Por exemplo, óxidos de terras raras são usados como corantes em vidros e mischmetal é usado como componente de algumas ligas metálicas. 
Tabela II. Aplicações de Terras-raras no Toyota Prius

\begin{tabular}{|c|c|}
\hline Aplicações & Elementos \\
\hline Motor elétrico híbrido e gerador & $\begin{array}{ll}\text { - } & \text { Neodímio } \\
\text { - } & \text { Praseodímio } \\
\text { - } & \text { Disprósio } \\
\text { - } & \text { Térbio } \\
\end{array}$ \\
\hline Vidro do farol & - $\quad$ Neodímio \\
\hline Motores elétricos & - Ímãs NdPr \\
\hline Conversor catalítico & $\begin{array}{ll}\text { - } & \text { Cério } \\
\text { - } & \text { Lantânio }\end{array}$ \\
\hline Bateria de $\mathrm{NiMH}$ híbrido & $\begin{array}{ll}\text { - } & \text { Lantânio } \\
\text { - } & \text { Cério } \\
\end{array}$ \\
\hline Aditivo do combustível diesel & $\begin{array}{ll}\text { - } & \text { Cério } \\
\text { - } & \text { Lantânio } \\
\end{array}$ \\
\hline Vidros e espelhos & - Cério \\
\hline Tela de cristal líquido & $\begin{array}{ll}\text { - } & \text { Európio } \\
\text { - } & \text { Ítrio } \\
\text { - } & \text { Cério }\end{array}$ \\
\hline Sensores de componentes & - Ítrio \\
\hline
\end{tabular}

\section{1 Ímãs Permanentes}

Atualmente, a maioria dos ímãs utilizados baseia-se na composição ( $\mathrm{NdPr}) \mathrm{FeB}$, às vezes com adições de disprósio. Esses ímãs são especialmente adequados em aplicações que requerem miniaturização, por exemplo em alto falantes de telefones celulares. A tendência atual é a instalação de turbinas eólicas cada vez maiores. Essas turbinas gigantes necessitam de ímãs de terras raras [10]. A explicação é que se ímãs de terras raras forem substituídos por ímãs de ferrite, isso aumentaria muito o peso dessas turbinas [11], [12], [13].

Para aplicações em alta temperatura, ímãs da família SmCo são mais adequados. Ímãs desse tipo estão em desuso, especialmente devido ao alto custo do cobalto. Um material muito interessante, as ligas do tipo SmFeN, não se tornaram comerciais, devido a instabilidade do nitrogênio na estrutura $\mathrm{Sm}_{2} \mathrm{Fe}_{17} \mathrm{~N}_{3}$.

Existem três tipos principais de motores de alto desempenho: (i) sem ímãs permanentes, (ii) com ímãs de ferrite de estrôncio (iii) com ímãs de terras raras. Todas as três soluções são possíveis [14]. Os motores dos veículos da Tesla Motors não usam ímãs permanentes, porém existem ímãs de terras raras nos motores da maioria dos carros elétricos, como o Nissan Leaf [14], [15] e BMW i3, e em carros híbridos como o Toyota Prius e Chevy Volt.

\subsection{Fósforos luminescentes}

Uma aplicação importante de Európio é em lâmpadas fluorescentes, junto com outros fósforos, para produzir luz branca. Európio é responsável por vermelho e azul, e o Térbio pela luz verde, conforme mostra a Tabela III [16]. Esse sistema de geração de cores também é utilizado em televisores coloridos, no padrão RGB ("red-green-blue").

No caso de LEDs, um jeito mais simples e barato de produzir luz branca é reunindo um diodo emissor de azul (InGaN ou GaN) com um fósforo emissor de amarelo, como a granada (YAG):Ce ${ }^{3+}$, 
(YAG=yttrium aluminum garnet). Essa solução evita o uso dos caros elementos Európio e Térbio, e utiliza os baratos Ítrio e Cério.

Devido à substituição de lâmpadas fluorescentes por lâmpadas de LED, os preços de Európio e Térbio vêm despencando recentemente.

Tabela III. Composição de fósforos tricromáticos típicos de aluminatos e fosfatos incluindo relação de mistura [16]

\begin{tabular}{|c|c|c|c|}
\hline Cor & $\begin{array}{c}\text { Fósforo } \\
\text { Aluminato }\end{array}$ & $\begin{array}{r}\text { Fósforo } \\
\text { Fosfato }\end{array}$ & Relação de mistura \\
\hline Vermelho & \multicolumn{2}{|c|}{ Y2O3: $\mathrm{Eu} \mathrm{(YOX)}$} & $33-71 \%$ \\
\hline Verde & CeMgAl11019: Tb (CAT) & LaPO4: Ce, Tb (LAP) & $29-40 \%$ \\
\hline Azul & BaMgAl10017: $\mathrm{Eu}(\mathrm{BAM})$ & $(\mathrm{Sr}, \mathrm{Ca}, \mathrm{Ba}) 10(\mathrm{PO} 4) 6 \mathrm{Cl} 2: \mathrm{Eu}$ (SCA) & $0-30 \%$ \\
\hline
\end{tabular}

\subsection{Catálise}

Uma aplicação comum de terras raras é em catálise [17]. Refino de petróleo usa zeólitos contendo lantânio, e pelo menos a Petrobrás precisa de 900.000 toneladas por ano de $\mathrm{La}_{2} \mathrm{O}_{3}$. Cério é utilizado em catalisadores automotivos.

\subsection{Lasers}

Uma aplicação relevante de $\mathrm{Nd}$ é em lasers do tipo $\mathrm{Nd}: \mathrm{YAG}$, uma granada ítrio-alumínio dopada com neodímio $\mathrm{Nd}: \mathrm{Y}_{3} \mathrm{Al}_{5} \mathrm{O}_{12}$.

\subsection{Sensores}

Um exemplo clássico é a liga Terfenol-D, usada em sensores, com formula $\mathrm{Tb}_{\mathrm{x}} \mathrm{Dy}_{1-\mathrm{x}} \mathrm{Fe}_{2}(\mathrm{x}$ 0.3). Essa liga é utilizada como sensor magnetostrictivo.

\subsection{Baterias}

As baterias $\mathrm{Ni}-\mathrm{M}-\mathrm{H}$ já foram as principais baterias comerciais, mas agora vem sendo suplantadas pelas baterias de Lítio íon. A BASF promete um grande aperfeiçoamento das baterias $\mathrm{Ni}-\mathrm{M}-\mathrm{H}$ para um futuro próximo [18]. Uma aplicação clássica das baterias Ni-M-H foi o Toyota Prius, que a partir de 2015 usa Li-íon.

\subsection{Polimento de vidro}

Óxido de Cério tem aplicação clássica em polimento de vidro. Por ser a terra rara mais abundante, é pouco provável o aumento do preço de Cério.

\subsection{Mischmetal e suas aplicações}

Mischmetal é usado como elemento de liga em ferros fundidos e em algumas ligas especiais. Era produzido no Brasil pela CIF - Companhia Industrial Fluminense, próximo a São João del Rei MG, até meados dos anos 1990 [19]. Algumas baterias do tipo Ni-M-H fazem uso de $\mathrm{M}=$ mischmetal. 


\section{EVOLUÇÃO DOS PREÇOS E SITUAÇÃO DO MERCADO}

A situação do mercado é muito importante, e determina se vale a pena fazer investimentos em terras-raras. $O$ aumento de preço de terras-raras em 2010-2011 foi em grande parte artificial. Em 7 de setembro de 2010 ocorreu um incidente com barco da guarda costeira japonesa e um pequeno pesqueiro chinês. Como resposta houve uma interrupção das exportações de terras-raras da China para o Japão [20].

O pico de preços em 2010-2011 levou a 2 eventos diferentes: (i) substituição de terras raras, quando possível e (ii) outros mineradores entraram no mercado, inclusive muitos chineses também, para aproveitar os altos preços. A combinação desses dois fatores (i) e (ii) provoca superprodução de terras-raras atualmente.

A substituição de Lâmpadas CFL (fluorescentes) por lâmpadas de LED ocasionou forte decréscimo na demanda por Európio. Como consequência o preço do Európio atualmente é o mais baixo dos últimos 8 anos [21].

Aproveitando a alta de preços de 2010-2011, diversas mineradoras ocidentais entraram no segmento das terras raras. Porém, os baixos preços das terras raras em 2014 e 2015 ocasionaram dificuldades financeiras na Molycorp, que opera a mina de Mountain Pass na California $[22],[23],[24]$ na canadense Great Western [25], [26], proprietária da mina Sul-Africana de Steenkampskraal, e na australiana Lynas [27], [28]. Os atuais baixos preços de terras raras são atribuídos a superprodução na China [29].

A Tabela IV apresenta a evolução de preços de 2002 a 2011. A Tabela V a evolução de preços de 2010 a 2014, a Tabela VI apresenta preços em meados deste ano de 2015, e a Tabela VII mostra preços de setembro de 2015.

Neste cenário fica difícil a viabilidade de minas baseadas exclusivamente na exploração de terras-raras. A solução é explorar as terras-raras como subproduto de minas já existentes.

A evolução dos preços de terras raras de 2002 a 2011 é mostrada na Tabela IV, segundo dados do British Geological Survey [30]. No período de 2010 a 2014 a evolução de preços é mostrada na Tabela V, segundo o USGS americano [1]. Dados de meados de 2015 são mostrados na Tabela VI [31]. Alguns valores atuais estão mostrados na Tabela VII. Alg uns dados das Tabelas IV, V e VI estão reunidos na Fig. 1. Nota-se também que nos últimos 3 meses, de final de maio de 2015 a setembro de 2015, ver Tabelas VI e VII, os preços caíram significativamente.

Tabela IV. Preços de óxidos de terras raras 2002 a 2009 [30]

\begin{tabular}{|c|c|c|c|c|c|c|c|c|}
\hline Ano (pureza 99\% min) & \multicolumn{7}{|c|}{ Preço (\$ por kg) } \\
\hline & La & Ce & Nd & Pr & Sm & Dy & Eu & Tb \\
\hline $\mathbf{2 0 0 2}$ & 2.3 & 2.3 & 4.4 & 3.9 & 3.0 & 20.0 & 240.0 & 170.0 \\
\hline $\mathbf{2 0 0 3}$ & 1.5 & 1.7 & 4.4 & 4.2 & 2.7 & 14.6 & 235.4 & 170.0 \\
\hline $\mathbf{2 0 0 4}$ & 1.6 & 1.6 & 5.8 & 8.0 & 2.7 & 30.3 & 310.5 & 398.0 \\
\hline $\mathbf{2 0 0 5}$ & 1.5 & 1.4 & 6.1 & 7.6 & 2.6 & 36.4 & 286.2 & 300.0 \\
\hline $\mathbf{2 0 0 6}$ & 2.2 & 1.7 & 11.1 & 10.7 & 2.4 & 70.4 & 240.0 & 434.0 \\
\hline $\mathbf{2 0 0 7}$ & 3.4 & 3.0 & 30.2 & 29.1 & 3.6 & 89.1 & 323.9 & 590.4 \\
\hline $\mathbf{2 0 0 8}$ & 8.7 & 4.6 & 31.9 & 29.5 & 5.2 & 118.5 & 481.9 & 720.8 \\
\hline $\mathbf{2 0 0 9}$ & 4.9 & 3.9 & 19.1 & 18.0 & 3.4 & 115.7 & 492.9 & 361.7 \\
\hline
\end{tabular}


Tabela V. Preços 2010 a 2014 [1].

\begin{tabular}{|c|c|c|c|c|c|}
\hline Elementos & \multicolumn{5}{|c|}{ Preço (\$ por kg) } \\
\hline & $\mathbf{2 0 1 0}$ & $\mathbf{2 0 1 1}$ & $\mathbf{2 0 1 2}$ & $\mathbf{2 0 1 3}$ & $\mathbf{2 0 1 4}$ \\
\hline Ce óxido, 99\% min & $60-62$ & $40-45$ & $10-12$ & $5-6$ & $4-5$ \\
\hline Dy óxido, 99\% min & $285-305$ & $1.400-1.420$ & $600-630$ & $440-490$ & $320-360$ \\
\hline Eu óxido, 99\% min & $620-640$ & $3.780-3.800$ & $1.500-1.600$ & $950-1.000$ & $680-730$ \\
\hline La óxido, 99\% min & $59-61$ & $50-52$ & $9-11$ & 6 & 5 \\
\hline Mischmetal, 65\% Ce, 35\% La & $57-60$ & $47-49$ & $14-16$ & $9-10$ & $9-10$ \\
\hline Nd óxido, 99\% min & $86-89$ & $190-200$ & $75-80$ & $65-70$ & $56-60$ \\
\hline Tb óxido, 99\% min & $595-615$ & $2.800-2.820$ & $1.200-1.300$ & $800-850$ & $590-640$ \\
\hline
\end{tabular}

Tabela VI. Preços em 22/Maio/2015 [31]

\begin{tabular}{|c|}
\hline $\mathrm{Pr} / \mathrm{Nd}$ \\
\hline $\mathrm{Pr} / \mathrm{Nd}$ metal 99\% min FOB $66-69 \$ / \mathrm{kg}$ \\
\hline $\mathrm{Pr} / \mathrm{Nd}$ óxido $99 \% \min \mathrm{FOB} \quad 46-49 \$ / \mathrm{kg}$ \\
\hline Dy \\
\hline Dy metal 99\% min FOB $370-390 \$ / \mathrm{kg}$ \\
\hline Dy óxido $99 \% \min$ FOB $280-290 \$ / k g$ \\
\hline Fe-Dy (Dy 80\%) min FOB $285-295 \$ / k g$ \\
\hline La \\
\hline La metal 99\% min FOB $6.4-6.9 \$ / \mathrm{kg}$ \\
\hline La óxido $99.9 \% \mathrm{~min}$ FOB $2.5-2.8 \$ / \mathrm{kg}$ \\
\hline La óxido $99.999 \% \mathrm{~min}$ FOB $6.0-6.5 \$ / \mathrm{kg}$ \\
\hline $\mathrm{Ce}$ \\
\hline Ce carbonato $45 \%$ REO FOB $1.3-1.6 \$ / \mathrm{kg}$ \\
\hline Ce metal 99\% min FOB $6.7-7.2 \$ / \mathrm{kg}$ \\
\hline Ce óxido $99.9 \% \min$ FOB $2.3-2.6 \$ / \mathrm{kg}$ \\
\hline $\mathrm{Nd}$ \\
\hline Nd metal 99\% min FOB $66-69 \$ / \mathrm{kg}$ \\
\hline Nd óxido $99 \%$ min FOB $46-49 \$ / k g$ \\
\hline Sm \\
\hline Sm metal 99\% min FOB $17-20 \$ / \mathrm{kg}$ \\
\hline Sm óxido $99 \% \min$ FOB $2.4-2.7 \$ / \mathrm{kg}$ \\
\hline $\mathrm{Tb}$ \\
\hline Tb metal $99 \%$ min FOB 780-830 \$/kg \\
\hline Tb óxido $99.99 \% \min$ FOB $610-650 \$ / k g$ \\
\hline $\mathrm{Pr}$ \\
\hline Pr metal 99\% min FOB 95-100 \$/kg \\
\hline Pr óxido $99 \% \min$ FOB $65-68 \$ / k g$ \\
\hline Eu \\
\hline Eu óxido $99.99 \% \min$ FOB 300-330 \$/kg \\
\hline Gd \\
\hline Gd óxido $99 \% \min$ FOB $16-21 \$ / k g$ \\
\hline Gd óxido $99.99 \%$ min FOB $22-25 \$ / k g$ \\
\hline Y \\
\hline Y óxido $99.999 \%$ min FOB $6.8-7.1 \$ / \mathrm{kg}$ \\
\hline Er \\
\hline Er óxido $99 \% \min$ FOB $42-45 \$ / k g$ \\
\hline La/Ce mischmetal \\
\hline La/Ce mischmetal(La35\%,Ce65\%) FOB5.8-6.3\$/kg \\
\hline Mischmetal(grau de bateria) com baixo Zn \& Mg \\
\hline Mischmetal $23-25 \$ / \mathrm{kg}=$ com baixo $\mathrm{Zn} \& \mathrm{Mg}$ FOB \\
\hline
\end{tabular}


Tabela VII. Alguns preços em 01 setembro 2015 [32]

\begin{tabular}{|l|}
\hline \multicolumn{1}{|c|}{ Preços } \\
\hline Ce carbonato 45\% REO FOB 0.9-1.0 \$/kg \\
\hline La óxido 99.9\% min FOB 1.9-2.1 \$/kg \\
\hline Nd metal 99\% min FOB 49-50 \$/kg \\
\hline Nd óxido 99\% min FOB $37 \$ / \mathrm{kg}$ \\
\hline Pr óxido 99\% min FOB 52-54 \$/kg \\
\hline Dy óxido 99\% min FOB $205 \$ / \mathrm{kg}$ \\
\hline Tb óxido $99.99 \% \mathrm{~min}$ FOB $405 \$ / \mathrm{kg}$ \\
\hline Y óxido $99.999 \% \mathrm{~min}$ FOB $5.0-5.2 \$ / \mathrm{kg}$ \\
\hline
\end{tabular}

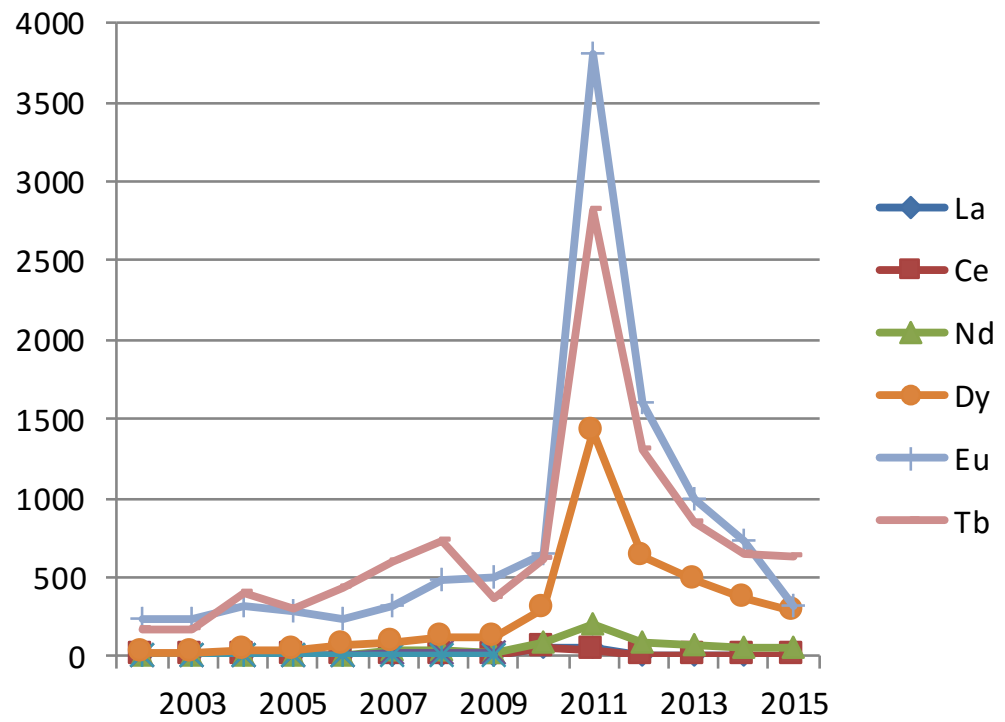

Figura 1. Evolução de preços de algumas terras raras de 2002 a 2015, em US\$ $/ \mathbf{k g}$.

\section{RESERVAS NO BRASIL}

O Brasil tem a segunda maior reserva oficial de terras-raras, conforme o USGS americano [1]. Nessa estimativa do USGS foram computadas apenas as reservas da CBMM em Araxá. Há muito mais locais com ocorrências relevantes de terras raras no Brasil, como mostra do na Fig. 2 e Tabela VIII. As terras raras pesadas têm maior valor do que as terras raras leves ( $\mathrm{Ce}, \mathrm{La}, \mathrm{Nd}$ e Pr). Entre as terras raras pesadas estão $\mathrm{Dy}$, Tb e Eu. O minério de terras raras mais comum no Brasil e no mundo é a monazita, um fosfato do tipo ( $T L) \mathrm{PO}_{4}$ onde $\mathrm{TL}=$ Terra-rara Leve. $\mathrm{A}$ monazita praticamente não contém terras raras pesadas. A Tabela IX reúne alguns dos locais com reservas significativas no Brasil. 


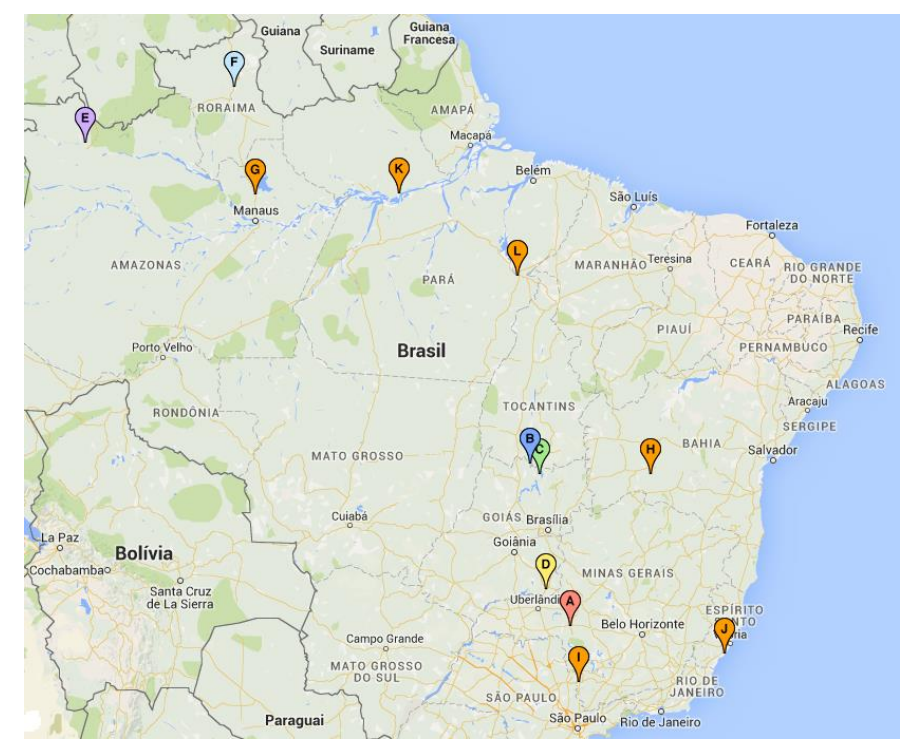

Figura 2. Locais com importantes reservas de terras raras no Brasil.

Tabela VIII - Locais com significantes reservas de terras raras apontados no mapa da Figura 2.

\begin{tabular}{|c|l|}
\hline A & Araxá \\
\hline B & Mata Azul \\
\hline C & Serra Verde \\
\hline D & Catalão \\
\hline E & Morro dos Seis Lagos \\
\hline F & Serra do Repartimento \\
\hline G & Pitinga \\
\hline H & Serra do Ramalho \\
\hline I & Morro do Ferro \\
\hline J & Guarapari \\
\hline K & Maicuru \\
\hline L & Salobo \\
\hline
\end{tabular}

Morro dos Seis Lagos, na Amazônia é uma da maiores reservas de nióbio e de terras raras no mundo. Morro dos Seis Lagos não deve ser explorada, pelo menos a curto e médio prazo, por estar situada em território indígena. Araxá tem importante reservas de nióbio e terras raras. $\mathrm{O}$ outro local onde nióbio é extraído no Brasil é Catalão, em Goiás, e também conta com elevado volume de terras raras leves.

Pitinga na Amazônia é local de uma mina de cassiterita, com alta quantidade de terras raras pesadas. A província estanífera de Goiás também tem expressiva quantidade de terras raras pesadas, sendo representada no mapa pelos projetos de Serra Verde e Mata Azul, ver Fig. 2.

Guarapari é uma praia famosa pelas suas areias monazíticas. Toda a costa brasileira, do norte do Rio de Janeiro até o Sul da Bahia, é rica em areia monazítica, que é trazida do fundo de mar pelas onda e se deposita sobre a areia. A monazita é de coloração amarelo-dourada. A cor preta da chamada areia monazítica vem da ilmenita $\mathrm{FeTiO}_{3}$, que costuma aparecer associada à monazita. 
Salobo é uma área da Vale com grandes reservas de cobre. Maicuru no Pará ainda precisa ser melhor investigado. Serra do Repartimento em Roraima também está em território indígena. Serra do Ramalho na Bahia tem geologia similar à da mina de Bayan Obo, na Mongólia (China). Morro do Ferro em Poços de Caldas é um local de pequenas reservas, para os padrões brasileiros.

A Tabela IX sumariza as reservas brasileiras não oficiais, que somadas superam as reservas oficias da China. A CBMM já produz concentrados de terras raras, pelo menos em escala piloto. Muitos outros projetos estão em avaliação. O projeto Serra Verde está em fase de estudos [40]. A província estanífera de Goiás, rica em terras raras pesadas, tem sido foco de diversas investigações $[41,42]$.

Tabela IX. Principais reservas de terras raras no Brasil

\begin{tabular}{|c|c|c|c|c|c|c|c|}
\hline Projeto & Minério & $\begin{array}{c}\text { Total } \\
\text { (MTon) }\end{array}$ & $\begin{array}{l}\text { Grau } \\
\% \text { REO }\end{array}$ & $\begin{array}{c}\text { REO } \\
\text { (MTOn) }\end{array}$ & Produção & $\begin{array}{c}\text { Terra Rara } \\
\text { Pesada }\end{array}$ & Ref. \\
\hline CBMM Araxá-MG & Monazita & 820 & 3.25 & 26.69 & Sim & Não & [33] \\
\hline MBAC Araxá-MG & Monazita & 21.94 & 3.99 & 0.9 & Não & Não & [33] \\
\hline Catalão-GO & Monazita & 120 & 5.5 & 6.6 & Não & Não & [34] \\
\hline Serra Verde Minaçu-GO & Argila iônica & 931 & 0.12 & 1.1 & $\begin{array}{l}2017- \\
2019\end{array}$ & Sim & {$[35]$} \\
\hline CREC Mata Azul - TO & "Granitóides" & $?$ & $?$ & ? & Não & Sim & [36] \\
\hline WMR Serra do Ramalho-BA & "Baotou-type" & ? & $\begin{array}{l}0.05- \\
2.61\end{array}$ & ? & Não & Não & {$[37]$} \\
\hline Pitinga AM & Xenotima & - & - & - & Não & Sim & [38] \\
\hline Morro dos Seis Lagos - AM & $\begin{array}{c}\text { Monazita/ } \\
\text { carbonatitos }\end{array}$ & 2900 & 1.4 & 43.5 & Não & ?? & [39] \\
\hline TOTAL & & & & 78.79 & & & \\
\hline
\end{tabular}

\section{VIABILIDADE ECONÔMICA}

Onde há nióbio, há terras raras leves. Onde há estanho há terras raras pesadas. Assim, é evidente a viabilidade das terras raras como subproduto de minas já existentes. Também em minas de tântalo há a possibilidade de terras raras leves e mesmo pesadas como subproduto. Uma das principais minas de tântalo do mundo está no Brasil, a Mibra ou atualmente AMG próximo a São João del Rei [43]. O USGS lista o Brasil como tendo a 2a maior reserva de tântalo no mundo, após a Austrália [44]. Tântalo também costumava ser produzido na mina de Pitinga, no Amazonas, pela mineração Taboca, junto com estanho [45].

Deve ser levado em conta que na monazita não há terras pesadas, e o lucro deve ser sustentado basicamente pela quantidade de $\mathrm{Nd}$ e $\operatorname{Pr}$ cujos óxidos, somados, consistem em aproximadamente $20 \%$ na monazita, ver Tabela X.

Tabela X. Porcentagem de elementos terras raras no minério de monazita da CBMM

\begin{tabular}{|l|l|l|l|l|l|l|l|}
\hline $\mathrm{La}_{2} \mathrm{O}_{3}$ & $\mathrm{CeO}_{2}$ & $\mathrm{Pr}_{6} \mathrm{O}_{11}$ & $\mathrm{Nd}_{2} \mathrm{O}_{3}$ & $\mathrm{Sm}_{2} \mathrm{O}_{3}$ & $\mathrm{Eu}_{2} \mathrm{O}_{3}$ & $\mathrm{Gd}_{2} \mathrm{O}_{3}$ & $\mathrm{~Tb}_{4} \mathrm{O}_{7}$ \\
\hline 30.6 & 44.1 & 4.6 & 15.3 & 1.58 & 0.38 & 1.28 & 0.12 \\
\hline $\mathrm{Dy}_{2} \mathrm{O}_{3}$ & $\mathrm{Ho}_{2} \mathrm{O}_{3}$ & $\mathrm{Er}_{2} \mathrm{O}_{3}$ & $\mathrm{Tm}_{2} \mathrm{O}_{3}$ & $\mathrm{Yb}_{2} \mathrm{O}_{3}$ & $\mathrm{Lu}_{2} \mathrm{O}_{3}$ & $\mathrm{Y}_{2} \mathrm{O}_{3}$ & - \\
\hline 0.42 & 0.06 & 0.15 & 0.01 & 0.05 & 0.01 & 1.29 & - \\
\hline
\end{tabular}


Para o minério da Tabela $X$, um projeto com custo U\$ 10/kg não é economicamente viável. O preço atual dos óxidos de La e Ce é aproximadamente 2 U\$ / kg, ver Tabelas VI e VII. Nesse preço está embutido o custo de separação de óxidos. Um detalhe importante é que não é necessário separar $\mathrm{Nd}$ e $\operatorname{Pr}$ para a produção de ímãs [8], o óxido misto de $\mathrm{Pr}$ e $\mathrm{Nd}$ na proporção $3 \mathrm{Nd}: 1 \mathrm{Pr}$ e também a liga metálica Nd75\%-Pr25\% tem grande valor comercial, ver Tabela VI.

Alguns projetos de produção de terras raras, como o de Kvanefjeld na Groenlândia [46] e Norra Karr na Suécia [47] não estão levando em conta que os preços de terras raras, especialmente o das terra raras pesadas como o Európio, decresceram significativamente em 2015. Existe nos Estados Unidos a monazita escura [48], [49], rica em Európio. Porém, a extração de terras raras da monazita escura talvez não seja viável considerando os preços atuais de Európio e outras terras raras pesadas.

A obtenção de terras raras como subproduto parece ser a opção mais adequada no presente momento, especialmente no Brasil. $\mathrm{O}$ alto preço de $\mathrm{Nd}$ e Prindica essa viabilidade.

É essencial para o Brasil o domínio da tecnologia de separação de óxidos em larga escala, e estudos nesse sentido estão sendo conduzidos pelo CETEM no Rio de Janeiro [50], [51].

Primeiro separa-se Ce, pois este tem valências +3 e +4 e isso pode ser aproveitado para facilitar a separação [50]. O óxido de La tem grande aplicação em catálise [51] e, portanto, grande interesse comercial, apesar do baixo preço atual.

A demanda de ímãs de terras raras é prevista para dobrar de 25.000 toneladas/ano em 2015 para 50.000 toneladas/ano em 2020 [52]. Significativa parte desse aumento é para aplicações em turbinas eólicas e indústria automobilística. A demanda por $\mathrm{Nd}$, $\mathrm{Pr}$ e Dy tende a continuar alta nos próximos anos, mas o interesse por Európio tende a decrescer.

\section{CONCLUSÕES}

Existe uma grande demanda por Nd, Pr e Dy atualmente, para a produção de ímãs. Turbinas eólicas são uma aplicação que requer enorme quantidade de ímãs. Motores de alta eficiência energética também devem pressionar a produção de Nd e Pr. A demanda por Európio e Térbio vem decrescendo, devido à substituição de lâmpadas fluorescentes compactas por lâmpadas de LED. Superprodução de terras-raras na China vem provocando drástica queda de preços, inviabilizando projetos de extração de terras-raras. No Brasil, terras raras podem ser obtidas como subproduto de minas de nióbio, tântalo ou estanho. É essencial o domínio da tecnologia de separação de óxidos pelo Brasil, pois o preço do concentrado de terras-raras é muito baixo. As reservas brasileiras de terras-raras são muito altas, podendo ser maiores do que as da China. $\mathrm{O}$ uso adequado das reservas de terras raras brasileiras pode impulsionar indústrias de alta tecnologia no Brasil.

\section{AGRADECIMENTOS}

CNPq, FAPERJ. 


\section{REFERÊNCIAS}

1. http://minerals.usgs.gov/minerals/pubs/commodity/rare_earths/mcs-2015-raree.pdf

2. http://www.tasmanmetals.com/s/Applications.asp

3. http://www.achrnews.com/articles/129322-april-7-2015-doe-announces-20-million-infunding-to-develop-high-efficiency-motors-and-drives

4. http://www.eia.gov/todayinenergy/detail.cfm?id=18151

5. http://www.iec.ch/etech/2015/etech_0315/tech-4.htm

6. D. Rodrigues, J. A. de Castro,. M. F. de Campos. Perspectives for Rare-Earth Magnets in Brazil. Proceedings of 23rd International Workshop on Rare Earth and Future Permanent Magnets and Their Applications REPM 2014, 2014, Annapolis, Maryland, USA. v. 1. p. 12-14

7. http://br.reuters.com/article/topNews/idBRSPE83NOAJ20120424

8. J. A. de Castro, .D. Rodrigues, M. F. de Campos. From Neodymium Oxide to NdFeB Alloy: An Overview on the Reduction Methods. Proceedings of 23rd International Workshop on Rare Earth and Future Permanent Magnets and Their Applications REPM 2014, 2014, Annapolis, Maryland, USA. v. 1. p. 358-360.

9. http://ecoinfo.cnrs.fr/article176.html

10. http://www.molycorp.com/molycorp-chosen-to-supply-rare-earths-for-use-in-highefficiency-siemens-wind-turbine-generators/

11. http://thinkprogress.org/climate/2015/05/20/3660677/bigger-taller-wind-turbines-willunlock-wind-power-across-united-states/

12. http://www.windpowerengineering.com/uncategorized/liebherr-tower-crane-lifts-a-fullypre-assembled-rotor-for-turbine-installation/

13. http://www.siemens.com/press/en/pressrelease/?press=/en/pressrelease/2015/windpower -renewables/pr2015050226wpen.htm\&content[]=WP

14. James D. Widmer, , Richard Martin, Mohammed Kimiabeigi. Electric Vehicle Traction Motors Without Rare Earth Magnets. Sustainable Materials and Technologies 3 (2015) 7-13.

15. http://www.johnwmorehead.com/nissan-leaf-ev-and-what-is-a-permanent-magnet-acmotor/

16. Quanyin Tan, Jinhui Li, Xianlai Zeng, Rare Earth Elements Recovery from Waste Fluorescent Lamps: A Review . Critical Reviews in Environmental Science and Technology, 45 (2015), 749776.

17. Reza Sadeghbeigi. Fluid Catalytic Cracking Handbook. Third edition 2012. ButterworthHeinemann, Amsterdam.

18. http://ecomento.com/2015/03/10/nimh-batteries-will-have-10-times-more-energy-densitybasf/

19. http://www.cif.ind.br/historia.html

20. http://www.bbc.com/news/business-11826870

21. http://www.metal-pages.com/news/story/88555/europium-oxide-market-hits-8-year-low- 
outlook-downbeat/

22. http://www.theenergycollective.com/geoffrey-styles/2243655/rare-earths-not-so-rare

23. http://www.businessinsider.com/molycorp-filing-for-bankruptcy-2015-6

24. http://fortune.com/2015/06/25/molycorp-bankruptcy/

25. http://investorintel.com/technology-metals-intel/great-western-and-lifton-on-lawyer-speak/

26. http://www.gwmg.ca/mining-operations/overview/steenka mpskraal-project-update

27. http://seekingalpha.com/article/3339415-lynas-was-finally-free-cash-flow-positive-in-q2-cy2015

28. http://investingnews.com/daily/resource-investing/critical-metals-investing/rare-earthinvesting/lynas-news-lynas-corporation-lyc-q3-results/

29. http://www.forbes.com/sites/timtreadgold/2015/05/15/chinese-rare-earth-glut-triggers-aprice-collapse-and-environmental-crisis/3/

30. http://www.bgs.ac.uk/research/highlights/2010/rare_earth_elements.html

31. http://www.info-re.com/index.php?/shop/article/1238

32. http://www.info-re.com/\#\&panel1-1

33. http://www.cetem.gov.br/286-ii-seminario-brasileiro-de-terras-raras-acontece-no-cetememnovembro

34. Carlos Cordeiro Ribeiro. Geologia, geometalurgia, controles e gênese dos depósitos de fósforo, terras raras e titânio do complexo carbonatítico Catalão I , GO. Tese de Doutorado, UnB, 2008. http://oatd.org/oatd/record?record=oai\\%3Abce.unb.br\\%3A2667

35. Alexandre Rocha, Don Schissel, Andreas Sprecher Paulo de Tarso, John R. Goode. Process development for the Serra Verde weathered crust elution-deposited rare earth deposit in brazil. In: Proceedings of the 52nd conference of metallurgists (com), october 27 to 31, 2013, Montréal, Canada, $\quad$ p. 277. http://web.cim.org/COM2014/conference/Rare_Earth_Elements_PROCEEDINGS_2013.pdf

36. http://www.marketwired.com/press-release/canada-rare-earth-integrates-rare-earthrefineries-with-rare-earth-properties-a-corporate-tsx-venture-II-1973940.htm

37. http://thiagolim4.wix.com/wmrport\#!_english/projects

38. http://www.scielo.br/pdf/aabc/v80n4/a12v80n4.pdf

39. http://meetingorganizer.copernicus.org/EGU2014/EGU2014-12709-1.pdf

40. http://www.nhm.ac.uk/our-science/our-work/sustainability/serra-verde-lateritic-ree.html

41. http://emps.exeter.ac.uk/csm/staff/iv217

42. http://repositorio.unb.br/bitstream/10482/15300/1/2013_IgorVasconcelosSantana.pdf

43. http://www.Ismbrasil.com.br/index.php?option=com_content\&view=article\&id=4\&ltemid=1 07\&lang $=\mathrm{pt}$

44. http://minerals.usgs.gov/minerals/pubs/commodity/niobium/mcs-2015-tanta.pdf

45. http://www.mtaboca.com.br/port/aempresa-historico.html 
46. http://www.ggg.gl/docs/ASX-announcements/Kvanefjeld-Feasibility.pdf

47. http://www.tasmanmetals.com/s/NewsReleases.asp?ReportID=691857\&_Type=News Releases\&_Title=Tasman-Announces-Results-Of-Pre-Feasibility-Study-For-The-Norra-KarrHeavy-...

48. http://www.prnews wire.com/news-releases/dark-monazi te-at-us-rare-earths-lemhi-passconfirmed-by-us-geological-survey-300085593.html

49. http://investorintel.com/technology-metals-intel/studies-suggest-cost-effective-domesticrare-earths-supply-united-states/

50. http://tecnologiammm.com.br/files/v11n3/v11n3a12.pdf

51. http://www.abq.org.br/cbq/2014/trabalhos/9/6259-19473.html

52. http://www.wrap.org.uk/sites/files/wrap/Wind\%20Turbine\%20Magnet\%20Study.pdf 